\title{
Myocardial perfusion imaging to guide percutaneous revascularization of chronic total occlusions: A gate keeper to the final frontier in PCI
}

\author{
Habib Samady, $M D,{ }^{a}$ and Gautam Kumar, $M B B S^{b}$
}

\section{See related article, pp. 563-568}

Percutaneous coronary intervention (PCI) of chronic total occlusions (CTO) is experiencing a renaissance due to novel equipment and techniques resulting in enhanced safety and rising success rates from $50 \%$ to the range of $80 \%-95 \%$. $^{1}$ This progress has challenged the prevailing therapeutic dogma of treating CTOs predominantly with either stand alone medical therapy or coronary bypass surgery $(\mathrm{CABG})$ when there is sufficient global disease burden. In fact, in an era of appropriate use criteria the presence of a CTO can be significant determinant for referral for $\mathrm{CABG}^{2,3}$ However, with lesion-specific physiologic assessment, a significant portion of non-CTO lesions in multi-vessel disease patients with CTOs are found to be non-hemodynamically significant, reducing the territories requiring revascularization and thus expanding percutaneous therapeutic options. ${ }^{4}$

Recent studies have documented benefits specific to successful CTO PCI with respect to improvement in symptoms, reduction in ischemia, and even a suggestion of better outcomes. ${ }^{5-7}$ However, in comparison with non-CTO PCIs, CTO PCI comes with a slightly higher risk of complications including coronary perforation, dissection, radiation-induced tissue damage, and contrast-induced nephropathy which can be mitigated by operator experience and careful patient selection. Angiographic features such as large amount of

From the Interventional Cardiology, ${ }^{\mathrm{a}}$ Emory University Hospital, Atlanta, GA. Interventional Cardiology (111C/D), , Atlanta VA Medical Center, Decatur, GA.

Reprint requests: Habib Samady, MD, Interventional Cardiology, Emory University Hospital, 1364 Clifton Road, Suite F606, Atlanta, GA 30322; hsamady@emory.edu.

J Nucl Cardiol 2013;20:504-5.

$1071-3581 / \$ 34.00$

Copyright (c) 2013 American Society of Nuclear Cardiology.

doi:10.1007/s12350-013-9704-4 myocardium subtended by the CTO or the presence of brisk collateral blood vessels may suggest potential benefit of revascularization in a vessel with sufficient blood flow to permit normal resting contractile function but inadequate to prevent exercise-induced ischemia. Other angiographic features such as the length of the occlusion, the presence of an antegrade beak or funneled cap, occlusion length, degree of tortuosity, calcification, or connecting septal channels can be critical in determining the likelihood of successful PCI and ultimately assessing the risk/benefit ratio the procedure. However, the goals of CTO revascularization, and indeed any revascularization for chronic angina syndromes, are predominantly to treat symptoms refractory to medical therapy and reduce ischemia, with the hope of improving prognosis. ${ }^{8}$ Therefore, the upstream decision to consider CTO PCI has to be a clinical and scintigraphic one and therefore there is a pressing need for data relating non-invasive imaging features to CTO PCI outcomes.

In this issue of the Journal, Wright et al ${ }^{9}$ retrospectively compare the association between ischemia on myocardial perfusion imaging (MPI) and the presence of collaterals on angiography with hard cardiac events (HCE) in 21 patients with CTOs treated medically over a mean follow up of 23 months (13-27 months range). The MPIs were retrospectively analyzed by a single observer and reported semi-quantitatively in a standard fashion with summed difference scores (SDS) of $>1$ defined as abnormal. Similarly, the angiograms were analyzed and the presence of collaterals was defined as Rentrop class $>0$. The authors found that 15 of $21(71.4 \%)$ patients had ischemia on MPI and 8 of $21(38.1 \%)$ patients had no collaterals. Furthermore, 9 of $15(60.0 \%)$ patients with ischemia on MPI had HCE $(P<.01$ compared to those without ischemia) and 5 of $8(62.5 \%)$ patients without collaterals had HCE $(P=.15$ compared to those with collaterals). The authors concluded that MPI in patients with CTO accurately predicted HCE, with extremely high sensitivity and negative predictive value, allowing for accurate triage of patients by MPI for consideration of revascularization if technically feasible. 
A number of limitations of this study are evident. First, is its limited sample size $(n=21)$. Second, is the potential bias introduced by its retrospective and nonrandomized study design resulting in potential confounders. But the message of the study seems consistent with the prevailing theme in invasive assessment of lesions purported to be causing chronic stable angina: functional assessment trumps anatomic assessment. ${ }^{10}$ In the nuclear sub-study of the COURAGE study (where patients with CTOs were excluded), patients with a large ischemic burden had better outcomes with revascularization. ${ }^{11}$ Improvement in ischemic burden has been documented following successful CTO PCI. ${ }^{12}$ In that study, a pre-PCI ischemic burden of $\geq 12.5 \%$ was found to be predictive of improvement and patients with an improvement of ischemic burden by $\geq 5 \%$ post-PCI had fewer clinical events, particularly death and target vessel revascularization. However, there is a paucity of clinical trials on the role of medical therapy vs CTO PCI that is currently being addressed by two trials underway in Europe and Asia (ClinicalTrials.gov identifiers NCT01760083 and NCT01078051, respectively).

Given the complexity of modern CTO PCI techniques, these procedures should only be performed in appropriately selected patients and in tertiary care centers with concentrated experience in one of the final frontiers in PCI. Non-invasive imaging is essential in selecting the appropriate patient who would benefit from CTO PCI. The threshold for percent of left ventricular ischemia on MPI is not established but it may be safe to speculate that the greater the ischemic burden, the more likely the benefit of revascularization. Certainly, patients with intractable anginal symptoms refractory to optimal medical therapy with lesser degrees of ischemia could also be considered for revascularization; however, it is safe to say that non-invasive imaging should be a gate keeper to the final frontier in PCI.

\section{Conflict of interest}

The authors have indicated that they have no financial conflict of interest.

\section{References}

1. Brilakis ES, Grantham JA, Rinfret S, Wyman RM, Burke MN, Karmpaliotis D, et al. A percutaneous treatment algorithm for crossing coronary chronic total occlusions. JACC Cardiovasc Interv 2012;5:367-79.
2. Patel MR, Dehmer GJ, Hirshfeld JW, Smith PK, Spertus JA. ACCF/SCAI/STS/AATS/AHA/ASNC 2009 appropriateness criteria for coronary revascularization: A report of the American College of Cardiology Foundation Appropriateness Criteria Task Force, Society for Cardiovascular Angiography and Interventions, Society of Thoracic Surgeons, American Association for Thoracic Surgery, American Heart Association, and the American Society of Nuclear Cardiology: Endorsed by the American Society of Echocardiography, the Heart Failure Society of America, and the Society of Cardiovascular Computed Tomography. Circulation 2009;119:1330-52.

3. Patel MR, Dehmer GJ, Hirshfeld JW, Smith PK, Spertus JA. ACCF/SCAI/STS/AATS/AHA/ASNC/HFSA/SCCT 2012 appropriate use criteria for coronary revascularization focused update: A report of the American College of Cardiology Foundation Appropriate Use Criteria Task Force, Society for Cardiovascular Angiography and Interventions, Society of Thoracic Surgeons, American Association for Thoracic Surgery, American Heart Association, American Society of Nuclear Cardiology, and the Society of Cardiovascular Computed Tomography. J Am Coll Cardiol 2012;59:857-81.

4. Nam CW, Mangiacapra F, Entjes R, Chung IS, Sels JW, Tonino PA, et al. Functional SYNTAX score for risk assessment in multivessel coronary artery disease. J Am Coll Cardiol 2011;58:1211-8.

5. Suero JA, Marso SP, Jones PG, Laster SB, Huber KC, Giorgi LV, et al. Procedural outcomes and long-term survival among patients undergoing percutaneous coronary intervention of a chronic total occlusion in native coronary arteries: A 20-year experience. J Am Coll Cardiol 2001;38:409-14.

6. Valenti R, Migliorini A, Signorini U, Vergara R, Parodi G, Carrabba $\mathrm{N}$, et al. Impact of complete revascularization with percutaneous coronary intervention on survival in patients with at least one chronic total occlusion. Eur Heart J 2008;29:2336-42.

7. Claessen BE, van der Schaaf RJ, Verouden NJ, Stegenga NK, Engstrom AE, Sjauw KD, et al. Evaluation of the effect of a concurrent chronic total occlusion on long-term mortality and left ventricular function in patients after primary percutaneous coronary intervention. JACC Cardiovasc Interv 2009;2:1128-34.

8. De Bruyne B, Pijls NH, Kalesan B, Barbato E, Tonino PA, Piroth $\mathrm{Z}$, et al. Fractional flow reserve-guided PCI versus medical therapy in stable coronary disease. N Engl J Med 2012;367:991-1001.

9. Wright S, Lichtenstein M, Grigg L, Sivaratnam D. Myocardial perfusion imaging (MPI) is superior to the demonstration of distal collaterals in predicting cardiac events in chronic total occlusion (CTO). J Nucl Cardiol 2013. doi:10.1007/s12350-013-9678-2.

10. Tonino PA, De Bruyne B, Pijls NH, Siebert U, Ikeno F, van't Veer $\mathrm{M}$, et al. Fractional flow reserve versus angiography for guiding percutaneous coronary intervention. N Engl J Med 2009;360:21324.

11. Shaw LJ, Berman DS, Maron DJ, Mancini GB, Hayes SW, Hartigan PM, et al. Optimal medical therapy with or without percutaneous coronary intervention to reduce ischemic burden: Results from the clinical outcomes utilizing revascularization and aggressive drug evaluation (COURAGE) trial nuclear substudy. Circulation 2008;117:1283-91.

12. Safley DM, Koshy S, Grantham JA, Bybee KA, House JA, Kennedy KF, et al. Changes in myocardial ischemic burden following percutaneous coronary intervention of chronic total occlusions. Catheter Cardiovasc Interv 2011;78:337-43. 